\title{
The Investigation of Patients with Retinal Vascular Occlusion
}

\author{
ELIZABETH M. GRAHAM
}

London

\begin{abstract}
Summary
The investigation of patients with retinal artery occlusion, retinal vein occlusion and cotton wool spots is discussed. The majority are due to either emboli or atheroma and occur in elderly patients. A full clinical history and examination remain the essential part of the investigation but the ophthalmologist must select patients in whom further investigation is warranted. The recent recognition of the importance of antiphospholipid antibodies and natural anticoagulant deficiency states in the pathogenesis of thrombosis has identified a group of young people in whom specific therapy may be indicated.
\end{abstract}

Every ophthalmologist encounters the unfortunate patient with sudden visual loss due to a recent retinal vascular occlusion. Two immediate questions arise: Firstly, can anything be done to improve or preserve vision? Secondly, what was the cause of the occlusion and are any practical precautions available to prevent a further attack? In the majority of cases substantial visual recovery is unusual and therefore the second question is vitally important. The ophthalmologist who first sees such a patient is responsible for identifying the cause of the occlusion, and consequently arranging appropriate referral for further management. This paper addresses the investigation of patients presenting to the ophthalmologist with either retinal artery occlusion, retinal vein occlusion or an isolated cotton wool spot.

\section{Retinal Artery Occlusion}

The majority of both central retinal artery occlusions and branch retinal artery occlusions are due to either emboli or atheroma and occur in patients with generalised arteriosclèrosis and hypertension.

A pertinent general medical history and examination accompanied by a thorough ophthalmic examination frequently identify the cause of the occlusion without resorting to special investigations. Salient features in the history are age, general health, family history of vascular disease, diet, drug and smoking habits. General examination should include measurement of pulse, blood pressure in both arms, auscultation of the heart and carotids and urinalysis for sugar and protein.

-The eye examination is often diagnostic and important things to look for are:

(i) evidence of local ocular disease, eg, episcleritis or scleritis, anterior segment inflammation, arteriolar loop, drusen of the optic nerve.

(ii) evidence of generalised retinal vascular disease, hypertensive or diabetic retinopathy.

(iii) presence of emboli and the nature of the embolus-white and calcific, refractile (cholesterol) or pale fibrin platelet plaques.

Special investigations are directed towards the cause of the vascular disease and the function of the heart (Table I). Essential tests in all patients are a full blood count, ESR, blood 
Table Ia Investigation of embolic retinal artery occlusion

\begin{tabular}{|c|c|c|c|}
\hline $\begin{array}{l}\text { TYPE OF } \\
\text { EMBOLUS }\end{array}$ & CALCIFIC & FIBRIN PLATELET & CHOLESTEROL \\
\hline ORIGIN & $\begin{array}{l}\text { aortic or } \\
\text { mitral valve } \\
\text { Bulse } \\
\text { Buscultation } \\
\text { Echocardiogram } \\
\text { Electrocardiogram } \\
\text { Cardiology Referral }\end{array}$ & $\begin{array}{l}\text { heart valve or } \\
\text { neck vessels }\end{array}$ & $\begin{array}{l}\text { Blood Pressure in both arms } \\
\text { Carotid Bruit } \\
\text { Ophthalmodynometry } \\
\text { Blood Lipids } \\
\text { Smoking } \\
\text { Consider Neurology Referral } \\
\text { Consider Digital Subratction } \\
\text { Angiography } \\
\text { Trial of Aspirin }\end{array}$ \\
\hline
\end{tabular}

Table Ib Investigation of non embolic retinal artery occlusion

Pulse

Blood pressure

Carotid bruit

Smoking habits

Urinalysis

Blood glucose

Blood lipids

ESR

VDRL TPHA glucose and lipid screen. Several points are worth remembering. Calcific retinal emboli originate from either the aortic or mitral valve. ${ }^{1,2}$ An urgent opinion from a cardiologist should be sought as frequently early valve replacement is the best treatment.

In young patients retinal artery occlusions are often due to emboli from the heart, although mitral valve prolapse has been incriminated in the past. ${ }^{3}$ A recent study of amaurosis fugax and retinal artery occlusion in people under 45 years of age found the incidence of mitral valve prolapse was $6.5 \%$ in both the patient group and in the general population ${ }^{4}$ casting doubt upon the previous assumption that mitral valve prolapse is of pathogenetic significance.

In elderly patients giant cell arteritis must never be forgotten as $20 \%$ of patients who lose vision do so from central retinal artery occlusion; the remaining $80 \%$ suffering from posterior ciliary artery occlusion. ${ }^{5}$

In young patients with 'negative' history and examination a systemic vasculitis (PAN or SLE) should be suspected. Retinal artery occlusion associated with migraine is well documented. ${ }^{6}$ However, the assumption that migraine is the cause of the occlusion is dangerous and this diagnosis should stand only when all other possibilities have been excluded.

\section{Isolated Cotton Wool Spot}

Cotton wool spots are commonly seen as part of a diabetic or hypertensive retinopathy. An isolated cotton wool spot is unusual, and even though it is often an incidental finding it may herald severe systemic disease. The cotton wool spot is produced by occlusion of the precapillary arterioles and is a reflection of the breakdown of retrograde and orthograde axoplasmic flow: the axoplasmic debris accumulates at the junction of healthy and anoxic retina and causes a dense white fluffy appearance. ${ }^{7,8}$ The presence of a cotton wool spot therefore indicates blockage of a retinal arteriole which may be due to abnormalities of the vascular endothelium, blockage by abnormal erythrocytes or unusual emboli (see Table II). The macroscopic and microscopic features of a cotton wool spot are always the same regardless of its cause. ${ }^{9}$

The patient who presents with an isolated cotton wool spot requires the same general medical history and examination as the patient with the retinal artery occlusion. However, the isolated cotton wool spot is unlikely to be due to an embolic phenomenon but more likely to be due to arterial disease, particularly a systemic vasculitis. The investigations are summarised in Table III. Giant cell arteritis is usually easy to diagnose clini- 
Table II Causes of cotton wool spots

\begin{tabular}{ll}
\hline Abnormalities of & Arteriosclerosis \\
vascular endothelium & $\begin{array}{l}\text { Diabetes mellitus } \\
\text { Hypertension } \\
\text { Systemic vasculitis } \\
\text { (SLE, PAN, GCA, scleroderma) }\end{array}$ \\
& Radiation retinopathy \\
& Human immunodeficiency virus \\
Abnormal erythrocytes & Haemoglobinopathies \\
Unusual emboli & Fat \\
& Talc \\
\hline
\end{tabular}

cally and the diagnosis is supported by the ESR and confirmed by the temporal artery biopsy. The presence of cotton wool spots in these patients means that the retinal circulation as well as the posterior ciliary circulation is involved in the disease progress and that immediate treatment with systemic steroids is imperative to prevent further visual loss.

The other systemic vasculitides associated with cotton wool spots are systemic lupus erythematosus (SLE),${ }^{10}$ polyarteritis nodosa (PAN) and rarely scleroderma. The clinical manifestations of these diseases are different: SLE commonly affects females particularly West Indians, who present with rashes, malaise, arthritis and renal problems, whereas PAN afflicts middle aged men who develop asthma, hypertension, myalgia and neuropathy. The simpleinvestigations to support the diagnosis of a systemic vasculitis remain the ESR and antinuclear antibodies: the latter are present in $90 \%$ of the sera of patients with SLE. Further classification of these antibodies reveals that patients with SLE have antibodies against double stranded DNA whereas patients with scleroderma and mixed connective tissue disease more frequently have antibodies against RNA. An important subgroup of patients with SLE have recently been identified who have phospholipid dependent clotting problems with autoantibodies against phospholipids. The three common types of these antibodies are 'reagin' in biological false positive syphilis serology, lupus anticoagulant and anticardiolipin antibodies. Patients with these antibodies and SLE, suffer recurrent arterial and venous thrombosis, spontaneous abortion, and retinal vascular occlusion. ${ }^{11}$ Moreover, there is a further important group of patients who do not have an autoimmune disease such as SLE but nevertheless have vaso-occlusive retinopathy associated with antiphospholipid antibodies. ${ }^{12,13}$

The diagnosis of PAN is made on clinical grounds and the pathological confirmation of a vasculitis in the medium sized arteries with leucocyte infiltration and fibrinoid necrosis. The ESR is raised, autoantibodies are present in low titres and immunoglobulin levels are usually high. However none of these tests are specific for PAN. Recently antineutrophil cytoplasmic antibodies (ANCA) have been found in the sera of many patients with two diseases related to PAN, namely Wegener's granulomatosis and microscopic polyarteritis nodosa. ${ }^{14}$ The latter is solely a renal disease and this test may therefore be useful in the investigation of the cause of an isolated cotton wool spot, particularly when associated with hypertension or other ophthalmological features such as scleritis or proptosis are also present.

In the majority of cases cotton wool spots are due to abnormalities of the vascular endothelium and this is secondary to an easily identified disease process such as diabetes mellitus (Table II). The question arises whether a local specific immune reaction against endothelial cells can occur in isolation: antiendothelial cell antibodies have been demonstrated in the sera of patients with inflammatory vasculitis ${ }^{15}$ but their importance in the pathogenesis of the cotton wool spot or other retinal vascular disease is not known.

The human immunodeficiency virus (HIV) is known to infect endothelial cells directly ${ }^{16}$ and cotton wool spots are the most frequent manifestation of AIDS to be seen in the fundus. ${ }^{17}$ Interestingly, cotton wool spots are not

Table III Investigation of the isolated cotton wool spot

\begin{tabular}{cl}
\hline Cause & Investigation \\
\hline 1. Systemic vasculitis & ESR \\
& Antinuclear antibodies \\
plus SLE & Anti DNA antibodies \\
PAN & Immunoglobulins \\
GCA & Eosinophil count \\
& Temporal artery biopsy \\
& C reactive protein \\
2. AIDS & HIV antibody \\
3. 'Nil obvious' & Blood pressure \\
& Blood glucose \\
& Smoking habits \\
\hline
\end{tabular}


seen in any asymptomatic HIV carriers but only patients with AIDS or AIDS related complex. High fibrinogen levels and raised circulating immune complexes are thought to contribute to their pathogenesis in this situation. ${ }^{18}$ The HIV antibody test should not be undertaken lightly by the ophthalmologist as the result has far reaching consequences for the patient. If HIV infection is suspected the patient should be referred to a special clinic (eg, genitourinary medicine, haemophiliac, drug addiction) for advice and counselling before the test is requested.

\section{Retinal Vein Occlusion}

Retinal vein occlusion commonly occurs in elderly patients and is another feature of generalised arteriosclerosis. A similar history and examination is required as from patients with retinal artery occlusion. However, slightly different points should be emphasised. Specific ophthalmological features associated with central retinal vein occlusion are open angle glaucoma and elevated intraocular pressure ${ }^{19}$ whereas hypermetropia is more prevalent in branch retinal vein occlusion. ${ }^{20}$

The two important contributory factors are vessel wall disease and increased blood viscosity. The investigations are summarised in Table IV. Hypertension and hyperlipidaemia are the most prevalent underlying medical conditions and an association with regular alcohol intake has also been suggested. ${ }^{20}$

Increase in blood viscosity is an important consideration in the pathogenesis of retinal vein occlusion although it is probable that this must be combined with vessel wall disease to produce actual occlusive phenomena. The cells in the blood have a greater influence on viscosity than plasma, and the red cells exert the greatest effect because of their large number than either leucocytes or platelets. The haemoglobin and packed cell volume reflect the number of red cells whereas a raised ESR suggests a raised plasma viscosity. Interestingly, Appiah and Trempe found an association between elevated ESR of unspecified cause and central retinal vein occlusion. ${ }^{20}$

Some systemic diseases are associated with an increased viscosity and therefore risk of thrombosis which includes retinal vein occlu- sion. Malignant disease, paraproteinaemia, nephrotic syndrome, tuberculosis and Behçet's syndrome are all examples of this. Behçet's disease is of particular importance to the ophthalmologist as severe inflammatory eye disease is an integral part of the symptom complex, and this diagnosis must always be considered in any patient who presents with a pan uveitis in association with branch retinal vein occlusion. Similarly, hypersensitivity reaction to tuberculous antigen can produce a florid pan unveitis and the picture of central retinal vein occlusion.

Recently, great interest has been directed towards the natural anticoagulants, which either prevent coagulation or precipitate fibrinolysis, and the possibility that deficiency of these natural anticoagulants may cause an increased tendency to clot (thrombophilia). Antithrombin III, heparin CoFactor II, platelet Factor III, protein $\mathrm{C}$ and protein $\mathrm{S}$ all act on the coagulation pathway whereas fibrinolysis is mediated by Factor XII, prekallikrein, urokinase and tissue plasminogen activator. The most common deficiencies recognised are those of antithrombin III, protein C and protein $S$ and assays are readily available in most routine laboratories. Homozygous Protein C deficiency and protein $\mathrm{S}$ deficiency are associated with recurrent thromboses. ${ }^{22,23}$ However the association between heterozygous Protein

Table IV Investigation of retinal vein occlusion

\begin{tabular}{|c|c|}
\hline Cause & Test \\
\hline \multicolumn{2}{|l|}{ 1. Vascular disease } \\
\hline \multirow[t]{3}{*}{ Hypertension } & Blood pressure \\
\hline & Urinalysis \\
\hline & Renal function \\
\hline \multirow[t]{3}{*}{ Hyperlipidaemia } & Cholesterol \\
\hline & Triglycerides \\
\hline & Lipoprotein profile \\
\hline \multicolumn{2}{|l|}{ Smoking } \\
\hline \multirow[t]{2}{*}{ Diabetes mellitus } & Urinalysis \\
\hline & Blood glucose \\
\hline \multirow[t]{2}{*}{ Systemic vasculitis } & ANA \\
\hline & Anti DNA antibodies \\
\hline \multirow[t]{9}{*}{ 2. Increased viscosity } & Full blood count \\
\hline & ESR \\
\hline & Fibrinogen \\
\hline & Packed cell volume \\
\hline & Platelet function tests \\
\hline & Plasma protein \\
\hline & Protein C \\
\hline & Protein S \\
\hline & Antithrombin III \\
\hline
\end{tabular}


C deficiency and thrombosis is not yet proven and it is possible other features are required for a thrombotic tendency. The relationship between Protein $\mathrm{C}$ deficiency and retinal vein occlusion is not known although one preliminary study suggested an association with branch retinal vein occlusion but not central retinal vein occlusion. ${ }^{24}$

The antiphospholipid antibodies are acquired immunoglobulins which encourage thrombosis by interfering with endothelial cells and preventing the interaction of natural anticoagulants with platelets. There is a significant association between patients with SLE with anticardiolipin antibodies and retinal vascular occlusions but not specifically retinal vein occlusion. ${ }^{24}$ Although this tendency was not found in a pilot study of patients with isolated idiopathic retinal vein occlu$\operatorname{sion}^{25}$ the test is still worth doing particularly in young patients.

\section{References \\ ${ }^{1}$ Ross Russell RW: The source of retinal emboli. Lancet 1968, 2: 789-92.}

${ }^{2}$ Arruga J and Sanders MD: Ophthalmological findings in 70 patients with evidence of retinal embolism. Ophthalmology 1982, 89: 1336-47.

${ }^{3}$ Caltrider ND, Irvine AR, Kline HJ, Rosenblatt A: Retinal emboli in patients with mitral valve prolapse. Am J Ophthalmol 1980, 90: 534-9.

${ }^{4}$ Tippin J, Corbett JJ, Kerber RE, Schroeder E, Thompson SH: Amaurosis fugax and ocular infarction in adolescents and young adults. Anns Neurol 1989, 26: 69-77.

${ }^{5}$ Wang FM and Henkind P: Visual system involvement in giant cell (temporal) arteritis. Surv Ophthalmol 1979, 32: 264-71.

${ }^{6}$ Hupp SL, Kline LB, Corbett JJ: Visual disturbances of migraine. Surv Ophthalmol 1989, 33: 221-36.

${ }^{7}$ Jampol LM: Arteriolar occlusive disease of the macula. Ophthalmology 1983, 90: 534-9.

${ }^{8}$ McLeod D, Marshall J, Kohner EM, Bird AC: The role of axoplasmic transport in the pathogenesis of retinal cotton wool spots. $\mathrm{Br} \mathrm{J}$ Ophthalmol 1977, 61: 177-91.

${ }^{9}$ Mansour AM, Jampol LM, Logani S, Henderly D: Cotton wool spots in Acquired Immunodeficiency Syndrome compared with Diabetes Mellitus, Systemic Hypertension and Central Retinal Vein Occlusion. Arch Ophthalmol 1988, 106: 1074-7.

${ }^{10}$ Lanham JG, Barrie T, Kohner EM, Hughes GRV. SLE retinopathy: evaluation by fluorescein angiography. Ann of Rheum Dis 1982, 41: 473-8.

${ }^{11}$ Asherson RA, Merry P, Acheson JF, Harris EN, Hughes GRV: Antiphospholipid antibodies: a risk factor of occlusive ocular vascular disease in systemic lupus erythematosus and the 'primary' antiphospholipid syndrome. Ann Rheum Dis 1989, 48: 358-61.

${ }^{12}$ Levine SR, Crofts JW, Lesser GR, Floberg J, Welch KMA: Visual symptoms associated with the presence of a lupus anticoagulant. Ophthalmology 1988, 95: 686-92.

${ }^{13}$ Kleiner RC, Najarian LV, Schatten S, Jabs DA, Patz A, Kaplan HJ: Vaso occlusive retinopathy associated with antiphospholipid antibodies. (Lupus anticoagulant retinopathy). Ophthalmology 1989, 96: 896-904.

${ }^{14}$ Savage COS, Wincarls CG, Jones S, Marshall PD, Lockwood $\mathrm{CH}$ : Prospective study of radio-immunoassay for antibodies against neutrophil cytoplasm in the diagnosis of systemic vasculitis. Lancet 1987, 1: 1389-93.

${ }^{15}$ Baguley E and Hughes GRV: Antiendothelial cell antibodies. (Editorial). J Rheumatol 1989, 16: 716-7.

${ }^{16}$ Pomerantz RJ, Kuritzkes DR, de la Monte SM, Rota TR, Albert D, Bor DH, Feldman EL, Schooley RT, Hirsch MS: Infection of the retina by human immunodeficiency virus type I. $N$ Engl J Med 1987, 317: 1643-7.

${ }^{17}$ Jabs DA, Green WR, Fox R, Polk BF, Bartlett JG: Ocular manifestation of Acquired Immune Deficiency Syndrome. Ophthalmology 1989, 96: 1092-9.

${ }^{18}$ Engstrom RE, Holland GN, Hardy D, Meiselman $\mathrm{HJ}$ : Abnormal blood rheologic factors in patients with human immunodeficiency virus-associated conjunctival and retinal microvasculopathy. Invest Ophthalmol Vis Sci (suppl) 1988, 29: 43.

${ }^{19}$ Frucht J, Shapiro A, Merin S: Intráocular pressure in retinal vein occlusion. Br J Ophthalmol 1984, 68: $26-8$.

${ }^{20}$ Appiah AP and Trempe CL: Differences in contributory factors among hemicentral central and branch retinal vein occlusion. Ophthalmology 1989, 96: 364-6.

${ }^{21}$ Dodson PM, Kubicki AJ, Taylor KG, Kritzinger EE: Medical conditions underlying recurrence of retinal vein occlusion. Br J Ophthalmol 1985, 69: 493-6.

${ }^{22}$ Seligsohn U, Berger A, Abend M, Rubin L, Attias D, Zivelin A, Rapaport SI: Homozygous protein C deficiency manifested by massive venous thrombosis in the new born. N Engl J Med 1984, 310: 559-62.

${ }^{23}$ Comp PC and Esmon CT: Recurrent venous thrombo-embolism in patients with partial deficiency of protein S. N Engl J Med 1984, 311: 1525-8.

${ }^{24}$ Chung MM, Trese MT, Hong YJ: Protein C levels in retinal vein occlusions. Invest Ophthal Vis Sci (suppl) 1989, 30: 477.

${ }^{25}$ Merry P, Acheson J, Asherson R, Hughes GRV: Management of retinal vein thrombosis. $\mathrm{Br} \mathrm{Med} J$ 1988, 296: 294. 